\title{
A new test of action verb naming: Normative data from 290 Italian adults
}

Costanza Papagno ${ }^{1,2}$, Alessandra Casarotti ${ }^{3}$, Barbara Zarino ${ }^{4}$, Davide Crepaldi $^{5}$

${ }^{1}$ CeRiN, CIMeC, University of Trento, Rovereto, Italy

${ }^{2}$ Department of Psychology, University of Milano-Bicocca, Milano, Italy

${ }^{3}$ Unit of Oncological Neurosurgery, Humanitas Research Hospital, Rozzano, Italy

${ }^{4}$ Department of Neuroscience and Sense Organs, Neurosurgery, Fondazione IRCCS

Ospedale Maggiore Policlinico, Milano, Italy

${ }^{5}$ International School for Advanced Studies (SISSA), Trieste, Italy

Corresponding author:

Costanza Papagno, MD, PhD

CeRiN, via Matteo del Ben 5/b

38068 Rovereto

ITALY

e-mail: costanza.papagno@unitn.it, costanza.papagno@unimib.it

orcid: 0000-0002-3659-6294

The Authors report no conflict of interest

The paper is under consideration at the journal "Neurological Sciences" 


\begin{abstract}
Verbs and nouns can be selectively impaired, suggesting that they are processed, at least in part, by distinct neural structures. While several tests of object naming are available, tasks involving action verb naming with normative data are lacking. We report the construction and standardization of a new test for the assessment of picture naming of actions. The test includes 50 stimuli, rigidly controlled for several confounding variables. Normative data on 290 Italian subjects pooled across homogenous subgroups for age, sex and education are reported. Multiple regression analyses revealed that age and education significantly correlated with the subject's score. In particular, increasing age negatively affected performance, while the performance increased with a higher education. In the clinical practice, the availability of equivalent scores will help the comparison with performance in the picture naming of objects. This test allows investigating action naming deficits in aphasic patients, in Parkinson's disease patients and in further neurodegenerative disorders, in which a specific impairment of action verbs is expected, filling a gap in the clinical neuropsychological assessment.
\end{abstract}

Key words: naming of actions; neuropsychological assessment; aphasia; noun-verb dissociation; Parkinson's disease 


\section{INTRODUCTION}

Verbs and nouns are word types that differ at many levels, namely semantic, lexical and grammatical level (see for example [1] for a review). Indeed, verbs are considered less referential [2] and concrete than nouns, and can take a number of different inflections. Moreover, verbs and nouns are processed by at least in part separate neural structures, as suggested by the fact that they can be selectively impaired, although which structures are involved in naming objects and verbs is still a matter of debate (see for example [3], or [4], for reviews; [5] for a recent study).

A deficit in lexical retrieval is a hallmark of all types of aphasia [6] and when evaluating picture naming both nouns and verbs, which in experimental designs refer to actions, should be tested, because they can be differentially impaired in neurological patients. Indeed, aphasic patients can show a disproportionate deficit in action naming as compared to naming of objects [7-10). Similarly, patients with non-fluent and semantic variants of Primary Progressive Aphasia demonstrate the same different pattern in naming verbs [11] similarly to vascular patients. Apart from this dissociation observed in aphasic patients, there are many additional pathological conditions in which a selective impairment of action verbs can be found. A selective impairment on oral confrontation naming of verbs was reported in a patient affected by Progressive Supranuclear Paralysis (PSP) [12]. Early stage Parkinson's disease (PD) patients show deficits in action naming ([13-17]; see 18 for review). Finally, action naming seems to be impaired in patients with amyotrophic lateral sclerosis [19].

Despite the observation of a disproportionate impairment of verb production in several diseases, in clinical practice action naming is not assessed as frequently as object naming. In fact, in Italian, as in many other languages, several standardized object naming tests are available (i.e., 20,21), but this is not the case for verbs. This is peculiar, since in order to judge whether a subject is performing at a normal level on a given test, it is necessary to partial out the influence of factors such as old age and low education, which can lower the scores [22]. Also, we are in need for stimuli that are controlled for frequency, imageability, instrumentality, prototypicality, age of acquisition and several other relevant variables, as it is usually the case for objects. In fact, there are database of action pictures for example in Russian [23], but no test has been constructed with this material. A battery for assessing object and action naming was developed in English by [24] in response to the lack of materials for investigating the difference between the availability of nouns and verbs. This battery, the Object and Action Naming Battery (OANB), has proved to be a useful tool in clinical practice and has been adapted to several languages such as Spanish [25], French [26], Dutch [27], and Saudi Arabian [28]. The OANB is a comprehensive naming battery that consists of 162 black and white line drawings 
of objects and 100 of action. This battery has been used also to assess noun and verbs in Spanish/English bilingual adults [29]. Another available action naming task is included in the DuLIP (Dutch Linguistic Intraoperative Protocol, [30]), but this battery is designed for intraoperative language mapping. The DuLIP was tested on 250 healthy adult volunteers. Action naming consists of 60 stimuli, and retrieval of the verb in the third person singular is required, in order to test also syntactic processing. However, as far as we understand, there are no adjusted scores, although a significant effect of age and education was found.

Normative data for naming are of course specific for each language and population, as well as several relevant variables, such as frequency and age of acquisition. From this perspective, an interesting effort was recently carried out by [31], who developed a set of 750 color drawings for both objects and actions, which they validated across 7 different languages. This is the only proper resource that might be applied cross-linguistically, as far as we are aware. However, the battery was only validated on adult, unimpaired speakers, which makes its suitability for brain-injured patient assessment and research unclear.

An action naming test for Italian was developed a few years ago by [32], which was indeed specifically tailored towards aphasic patients. However, these authors did not validate their battery, across a span of unimpaired speakers of different ages and education levels — but the effects of these demographic variables are to be taken into account if one wants to use the test outside of the original research context, as a general-purpose assessment tool. Therefore, our aim was to collect normative data for this picture naming test of actions, selecting controlled stimuli on a population that included people from 20 to $>85$ years, given the increase in the average length of life.

\section{MATERIALS AND METHODS}

\section{PARTICIPANTS}

Two hundred and ninety healthy Italian volunteers $(n=290)$ were included in the study, 142 males and 148 females. Mean age and mean education were 54,10 years (range 19-98, $\mathrm{SD}=19,2$ ) and 12,26 years (range 3-23, $\mathrm{SD}=4.26$ ), respectively. Inclusion criteria were: (i) age $\geq 18$ years, (ii) absence of neurological or psychiatric diseases, or of any potential medical diseases, in addition to no history of alcohol and/or drug abuse, (iii) right handedness. Participants were selected in order to balance demographic variables (age, education, sex) that may affect performance (see Table 1). They were divided in seven groups according to age $(19-29,30-39,40-49,50-59,60-69,70-79$, $\geq 80)$, and in five groups according to education $(\leq 5,6-8,9-13,14-16, \geq 17)$. They were recruited from different sources: (i) relatives, friends and colleagues of the authors, (ii) spouses, relatives and caregivers of in-and out-patients of the hospital where 
two authors (BZ and AC) worked (Fondazione IRCCS Ca' Granda - Ospedale Maggiore Policlinico, Milan, Italy and Istituto Clinico Humanitas). The ethnic background of all participants was Caucasian, and they were all native Italian speakers. At the time of testing, they were all living in Italy. They also received education in Italian. Participants did not receive any financial reimbursement or any other compensation. The study was approved by the local ethical committee of the University of Milano-Bicocca.

\section{---- Insert Table 1 about here----}

\section{MATERIAL}

A picture naming test of 50 actions was taken from [32]. Items in that study were selected from an initial set of 123 line-drawings, and were included in the battery when name agreement (as obtained from an independent sample of participants in the original study).

The major lexical-semantic variables that affect lexical retrieval (namely, word frequency, imageability, age of acquisition and word length) were collected. Oral word frequency was computed as stem frequency, i.e. considering the total frequency of all inflected forms corresponding to a single citation form. Picture typicality was assessed by asking 23 healthy subjects, who did not take part in the normative data collection, to score each item using a seven-point scale according to how closely each drawing represented a prototypical exemplar of the action underlying the target verb. A rating of 1 indicated very low typicality while 7 corresponded to the highest typicality. Similarly, a seven-point scale was used to assess imageability: the same control subjects were asked to score each word according to the ease with which it evoked a mental image. Finally, a similar procedure was used to collect rating on age of acquisition: subjects were asked to score each word on a nine-point scale where 1 corresponded to acquisition within the second year of life, 2 within the third year of life and so on until 9. A further group of 25 healthy undergraduate students $(11 \mathrm{~F}$ and $14 \mathrm{M}$; age $24.5 \pm 5.7$ y) were asked to score each item using a $1-7$ scale according to how much each verb does imply the production of non-automatized, complex movements (see [32] for ratings scores).

\section{ACTION NAMING TEST}

Each participant was tested individually inside the Hospital, in a quiet room. Items were presented on a computer screen in PowerPoint format. Participants were asked to name 50 stimuli, namely black-and-white drawings representing actions [32]. One point was assigned for each correct response (range 0-50). The first three items were examples. Verbs could be produced either in a nonfinite (for example, camminare, to walk) or finite form (for example, cammina, he is walking) (see Table 2). Latencies longer than 3s and self-repairs were scored as errors. The examiner said: "Now I show 
you pictures of actions, you should tell me the verb in nonfinite or finite form. For example,...”. Responses given by $5 \%$ of the control subjects were accepted as an alternative correct answer.

------ Insert Table 2 about here -----

\section{STATISTICAL ANALYSIS}

Statistical analysis and scoring were performed according to the method described by [33]. Multiple regression analyses were first performed to establish which demographic variables had to be included in the final model, which was based on significance testing on the individual predictors. We considered gender, age and years of education, including their quadratic, logarithmic and square-root terms. For each variable, the first step was to identify the linear model through a covariance analysis, which proved to be the most effective in reducing residual variance.

Based on the relative influence of those variables that had a significant effect, correction grids were derived to adjust, when necessary, the performance of each newly tested participant for the effect of age, education, and gender. Adjusted scores were then used to compute tolerance limits. A subject's score is considered normal when it lies within the highest $95 \%$ of the population, whereas it is taken as pathological if it falls within the lowest $5 \%$. Inferential cut-off scores were then derived for each gender, age and education band, based on this approach More generally, adjusted scores were transformed into a 5-point interval scale, from 0 to 4 equivalent scores, following a method used for other neuropsychological tests [34]. Zero corresponds to a score below the $5 \%$ tolerance limit, and is therefore deemed pathological. The scores 1,2 , and 3 are intermediate, and cover from the $5^{\circ}$ to $20^{\circ}$ percentile, from the $20^{\circ}$ to $35^{\circ}$ percentile, and from the $35^{\circ}$ to $50^{\circ}$ percentile in the population, respectively. A score of 4 corresponds to a performance fully within the normal range, and flags a higher score than the population median. Equivalent scores simply combine non-parametric tolerance limits and the relevant demographic adjustment [33].

\section{RESULTS}

The mean and median adjusted scores are reported in Table 3, together with the values delimiting the different equivalent scores. As described above, a multiple regression analysis with age, gender, and education as independent variables was performed. Overall, the model significantly captures variance in the scores $[F(3,287)=48.017, p<$ 0.0001]. Age and education significantly affected the participants' performance $(t=-2.49, p=0.013 ; t=2.725, p<0.01$ respectively), while gender $\operatorname{did}$ not $(\mathrm{t}=-1.47$, n.s. $)$. 
The linear model that proved to be the most effective in reducing the residual variance for the action naming was $\mathrm{y}=$ Raw score-[- $0.068 \times$ (age-54.1)]-[0.305 x (education 2.2586)]

Correction grids are reported in Table 4 (See Appendix for an example of how to use correction grids).

---- Insert Tables 3 and 4 about here---

\section{DISCUSSION}

We collected normative data for action naming in order to provide a tool for the testing of Italian speakers, and particularly brain injured patients. We considered a wide age interval, spanning from 19 over 80 years, due to the increased population mean age. A significant effect of age and education was found as in previous standardizations of language tasks on the Italian population [34-36]. We observed, in particular, that performance decreased with aging, as it occurs in the majority of neuropsychological tests (with the interesting exception of naming by description [35]). Education, on the contrary, improved performance. Sex had no effect on it, instead.

Naming tasks are among the most widely used tests in neuropsychology but till now, in Italy, there were no standardized tests with norms for action naming. The present test will be particularly useful also in patients with PD, to detect minimal language impairment that should appear especially in lexical retrieval of action naming. Moreover, this task has been included in a battery to assess language patients with low grade gliomas [37], because standardized language batteries are not sensitive enough in these patients. According to [38] verb tasks are preferable to object naming tasks in the case of frontal tumors, as lesion and neuroimaging data demonstrate that these regions play a critical role in verb processing. However, this observation is not entirely consistent. For example, VLSM data collected on 102 patients who underwent surgery for a left frontal or temporal glioma showed that action verbs scores correlated with the left parieto-temporal region, but not with frontal areas [5]. Differently, Akinina et al [39] showed involvement of frontal regions, using VLSM, in 40 left hemisphere stroke patients, but did not find significant results in temporal or parietal areas. Finally, Hauck and colleagues [40] compared language activation sites on 19 healthy participants whit fMRI and repetitive navigated transcranial magnetic stimulation (rTMS). Verb generation and action naming during fMRI activated supramarginal gyrus (SMG) within the parietal lobe, and fusiform gyrus; whereas rTMS evoke a considerable number of errors in middle temporal gyrus (MTG) and superior temporal gyrus (STG), in temporal areas, and in middle frontal gyrus (MFG), in prefrontal cortex. Overall, the evidence from the literature is still discordant and inconclusive. Further investigation with appropriate tests is required. We hope that our new tool will be of help both in clinic and research neuropsychology. 


\section{REFERENCES}

[1] Druks J (2002) Verbs and nouns. A review of the literature. J Neuroling 15: 289-315.

[2] Gentner D (1982) Why nouns are learned before verbs: Linguistic relativity versus natural partitioning. In S. Kuczaj II (ed.) Language development, vol 2. Language, thought and culture. Hillsdale, NJ: Lawrence Erlbaum Associate, pp. 301-304.

[3] Cappa SF, Perani D (2003) The neural correlates of noun and verb processing. J Neuroling16: 183-189.

[4] Crepaldi D, Berlingeri M, Cattinelli I, Borghese NA, Luzzatti C, Paulesu E (2013). Clustering the lexicon in the brain: a meta-analysis of the neurofunctional evidence on noun and verb processing. Front Hu Neurosci 7: 303.

[5] Pisoni A, Mattavelli G, Casarotti A, Comi A, Riva, M, Bello L, Papagno C (2018) Object-action dissociation: a voxel-based lesion-symptom mapping study on 102patients after glioma removal. NeuroImage Clin 18: 986-995. https://doi.org/10.1016/i.nicl.2018.03.022

[6] Laine M, Martin N (2006) Anomia: Theoretical and clinical aspects.. Taylor and Francis Hove, United Kingdom.

[7] Miceli G, Silveri C, Villa G, Caramazza, A. (1984). On the basis for the agrammatic's difficulty in producing main verbs. Cortex 20 (2): 207-220.

[8] Miceli G, Silvieri C, Nocentini U, Caramazza A (1988). Patterns of dissociation in comprehension and production of nouns and verbs. Aphasiology 2(3/4): 351-358. doi :10.1080/02687038808248937

[9] Baxter DM, Warrington EK (1985) Category specific phonological dysgraphia. Neuropsychologia 23: $653-666$.

[10] Zingeser L, Berndt RS (1990) Retrieval of nouns and verbs in agrammatism and anomia. Brain Lang 39(1): 14-32. doi: 10.1016/0093-934X(90)90002-X.

[11] Marcotte K, Graham NL, Black SE, Tang-Wai D, Chow TW, Freedman M, Rochon E, Leonard C (2014) Verb production in the nonfluent and semantic variants of primary progressive aphasia: The influence of lexical and semantic factors. Cogn Neuropsychol 31: 565-583.

[12] Daniele A, Barbier A, Di Giuda D, Vita MG, Piccininni C, Spinelli P, Tondo G, Fasano A et al. (2013). Selective impairment of action-verb naming and comprehension in progressive supranuclear palsy. Cortex 49: 948-960.

[13] Bertella L, Albani G, Greco E, Priano L, Mauro A, Marchi SA et al. (2002) Noun verb dissociation in Parkinson's disease. Brain Cogn 48: 277-280

[14] Cotelli M, Borroni B, Manenti R, Zanetti M,Are'valo A, Cappa SF, Padovani A. (2007). Action and object naming in Parkinson's disease without dementia. Eur J Neurol 14: 632-637.

[15] Péran, P., Cardebat, D., Cherubini, A., Piras, F., Luccichenti, G., Peppe, A., Caltagirone, C., (2009) Oject naming and action-verb generation in Parkinson's disease: a fMRI study. Cotyex 45: 960-971.

[16] Fernandino L, Conant LL, Binder, JR, Blindauer K, Hiner B, Spangler K, Desai,RH (2013). Parkinson's disease disrupts both automatic and controlled processing of action verbs. Brain Lang127: 65-74.

[17] Herrera E, Rodrìguez-Ferreiro J, Cuetos F (2012) The effect of motion content in action naming by Parkinson's disease patients. Cortex 48: 900-904.

18] Papagno C, Trojanoàà L (2018). Cognitive and behavioral disorders in Parkinson's disease: an update. I: cognitive impairments. Neurol Sci 39: 215-223. doi: 10.1007/s10072-017-3154-82.

[19] Papeo L, Cecchetto C, Mazzon G, Granello G, Cattaruzza T, Verriello L, Eleopra R, Rumiati RI (2015) The processing of action and action-words in amyotrophic lateral sclerosis patients. Cortex 64: 136-147.

[20] Catricalà E, Della Rosa P, Ginex V, Mussetti Z, Plebani V, Cappa SF (2013) An Italian battery for the assessment of semantic memory disorders. Neurol Sci 34: 985-993. doi: 10.1007/s10072-012-1181-z.

[21] Laiacona M, Barbarotto R, Baratelli E, Capitani E (2016). Revised and extended norms for a picture naming test sensitive to category dissociations. Neurol Sci 37: 1499-1510.

[22] Capitani E, Laiacona, M. (1997). Composite neuropsychological batteries and normative values. Standardisation based on equivalent scores, with a review of published data. J Clin Exp Neuropsychol 19: 795-809. doi:10.1080/01688639708403761

[23] Akinina Y, Malyutina S, Ivanova M, Iskra E, Mannova E, Dragoy O (2015) Russian normative data for 375 action pictures and verbs. Behav Res Met 47: 691-707.

[24] Druks J, Masterson J (2000). An Object and Action Naming Battery. Hove: Psychology Press

[25] Cuetos F, Alija M (2003) Normative data and naming times for action pictures. Behav Res Met, Instr Comput 35 : 168-177. doi:10.3758/BF03195508. 
[26] Schwitter V, Boyer B, Méot A, Bonin P, Laganaro M (2004). French normative data and naming times for action pictures. Behav Res Met, Instr Comput 36: 564-576. doi:10.3758/BF03195603

[27] Shao Z, Roelofs A,Meyer AS. (2014). Predicting naming latencies for action pictures: Dutch norms. Behav Res 46:274-283. doi:10.3758/s13428-013-0358-6.

[28] Alyahya RSW, Druks J (2016) The adaptation of the object and action naming battery into Saudi Arabic.

Aphasiology 30 (4): 463-482,

[29] Edmonds LA, Donovan NJ (2012) Item-level psychometrics and predictors of performance for Spanish/English bilingual speakers on an Object and Action Naming Battery. J Speech Lang Hear Res 55: 359-381.

[30] De Witte E, Satoer D, Robert E, Colle H, Verheyen S, Visch-Brink E, Marien P (2015) The Dutch linguistic intraoperative protocol: A valid linguistic approach to awake brain surgery. Brain Lang 140: 35-48.

[31] Duñabeitia JA, Crepaldi D, Meyer AS, New B, Pliatsikas C, Smolka E, Brysbaert M. (2018). MultiPic: A standardized set of 750 drawings with norms for six European languages. Quart J Exp Psychol 71: 808-816..

[32] Crepaldi D, Aggujaro S, Arduino LS, Zonca G, Ghirardi G, Inzaghi MG., et al. (2006) Noun-verb dissociation in aphasia: The role of imageability and functional locus of the lesion. Neuropsychologia 44: 73-89.

[33] Capitani, E. (1997). Normative data and neuropsychological assessment. Common problems in clinical practice and research. Neuropsychol Rehab 7: 295-309. doi:10.1080/ 713755543

[34] Spinnler H, Tognoni G. (1987). Standardizzazione e taratura italiana di test neuropsicologici [Italian standardization of neuropsychological tests]. Italian Journal of Neurological Science 6 (Suppl 8): 1-120.

[35] Novelli G, Papagno C, Capitani E, Laiacona M, Vallar G, Cappa SF (1986). Tre test clinici di ricerca e produzione lessicale: taratura su soggetti normali [Three clinical tests of verbal long-term memory: standardization on normal subjects]. Arch Neurol Psicol Psich 47: 477-506.

[36] Papagno C, Cappa SF, Garavaglia P, Capitani E, Laiacona M, Vallar G (1995) La comprensione non letterale del linguaggio: taratura su soggetti normali. Arch PsicoloNeurol Psichiat 56: 402-420.

[37] Papagno C, Casarotti A, Comi A, Gallucci M, Riva M, Bello L (2012). Measuring clinical outcomes in neurooncology. A battery to evaluate low-grade gliomas (LGG). J Neurooncol 108 (2): 269-75. doi:10.1007/s11060-0120824-5.

[38] Rofes A, Miceli G (2014). Language Mapping with Verbs and Sentences in Awake Surgery: A Review Neuropsychol Rev 24: 185-199.

[39] Akinina Y, Dragoy O, Ivanova MV, Iskra EV, Soloukhina OA, Petryshevsky AF, Fedina ON, Turken AU, Skklovsky VM, Dronkers NF, (2019) Grey and white matter substrates of action naming. Neuropsychologia 131: 249265. doi: 10.1016/j.neuropsychologia.2019.05.015.

[40] Hauck T, Probst M, Zimmer C, Ringel F, Meyer B, Wohlschlaeger A, Krieg SM (2019). Language function shows comparable cortical patterns by functional MRI and repetitive nTMS in healthy volunteers. Brain Imag Behav 13(4): 1071-1092. 


\section{APPENDIX}

To explain how to use the correction grid, we report an example of patient XZ, female, 60 years, 17 years of education, affected by non-fluent primary progressive aphasia. Her raw score was 44 . Given her age and education the raw score can be adjusted by subtracting 1.2 to the 44 . The adjusted score is therefore 42.8 , corresponding to an equivalent score of 2 , which is a normal performance. 


\section{TABLeS}

Table 1 - Distribution of the study group according to age and education level. Values are number of subjects

\begin{tabular}{|c|c|c|c|c|c|c|c|c|}
\hline \multicolumn{9}{|c|}{ Age, years } \\
\hline & $19-29$ & $30-39$ & $40-49$ & $50-59$ & $60-69$ & $70-79$ & $\geq 80$ & Total \\
\hline \multicolumn{9}{|c|}{ Educational level } \\
\hline \multicolumn{9}{|c|}{$\leq 5$} \\
\hline Men & 0 & 0 & 0 & 3 & 5 & 5 & 5 & 18 \\
\hline Women & 0 & 0 & 0 & 3 & 5 & 5 & 5 & 18 \\
\hline \multicolumn{9}{|l|}{$6-8$} \\
\hline Men & 3 & 5 & 5 & 5 & 5 & 5 & 3 & 31 \\
\hline Women & 2 & 5 & 7 & 6 & 5 & 5 & 5 & 35 \\
\hline \multicolumn{9}{|l|}{$9-13$} \\
\hline Men & 6 & 5 & 5 & 5 & 5 & 5 & 5 & 36 \\
\hline Women & 6 & 5 & 6 & 6 & 5 & 6 & 5 & 39 \\
\hline \multicolumn{9}{|l|}{$14-16$} \\
\hline Men & 5 & 5 & 3 & 5 & 2 & 1 & 3 & 24 \\
\hline Women & 5 & 6 & 5 & 5 & 2 & 2 & 0 & 25 \\
\hline \multicolumn{9}{|l|}{$\geq 17$} \\
\hline Men & 7 & 5 & 6 & 5 & 3 & 5 & 2 & 33 \\
\hline Women & 5 & 7 & 5 & 5 & 3 & 3 & 3 & 31 \\
\hline \multicolumn{9}{|l|}{ Total } \\
\hline Men & 21 & 20 & 19 & 23 & 20 & 21 & 18 & 142 \\
\hline Women & 18 & 23 & 23 & 25 & 20 & 21 & 18 & 148 \\
\hline
\end{tabular}


Table 2- Stimuli for the action naming task with accepted alternative responses.

$\begin{array}{ll}\text { Action } & \text { Alternatives }\end{array}$

Scrivere - to write - she is writing

Bere - to drink - he is drinking

Svegliarsi - to wake - he is waking up

Cadere - to fall - he is falling

Cascare

Sbadigliare - to yawn - he is yawning

Mordere/azzannare/morsicare - to bite - it is biting

Spingere - to push - he is pushing

Pattinare - to skate - she is skating

Spostare

Volare - to fly - it is flying

Imbucare - to post - he is posting

Arrestare/ammanettare - to arrest - he is arresting

Spedire

Salire - to climb - he is climbing

Gonfiare/pompare - to pump - he is pumping

Bussare - to knock - she is knocking

Pregare - to pray - he is praying

Baciare - to kiss - she is kissing

Nuotare - to swim - to swimming

Salutare - to greet - he is greeting

Ruggire - to roar - he is roaring

Fotografare - to photograph - she is photographing

Pelare - to skin - he is skinning

Scattare

Decollare - to take off - it is taking off

Sbucciare

Sanguinare - to bleed - he is bleeding

Soffiare - to blow - he is blowing

Affondare - to sink - it is sinking 


\begin{tabular}{|c|c|}
\hline Raccogliere - to pick - she is picking & Naufragare/Inabissarsi \\
\hline Crescere - to grow up - he is growing up & Cogliere \\
\hline \multicolumn{2}{|l|}{ Sciare - to ski - he is skiing } \\
\hline \multicolumn{2}{|l|}{ Brillare/luccicare - it shine - it is shining } \\
\hline Annaffiare - he water - he is watering & Splendere \\
\hline Legare - to tie - he is tieing & Innaffiare/Bagnare \\
\hline Affogare/annegare - to drown - he is drowning & Slegare \\
\hline \multicolumn{2}{|l|}{ Versare - to pour - he is pouring } \\
\hline Lanciare - to trow - he is trowing & Svuotare/Riempire \\
\hline Scoppiare - to brust - it is brusting & Tirare \\
\hline Camminare - to walk - he is walking & Esplodere \\
\hline Dimagrire - to slim - she is slimming & Passeggiare \\
\hline \multicolumn{2}{|l|}{ Piangere - to cry - she is crying } \\
\hline \multicolumn{2}{|l|}{ Guidare - to drive - he is driving } \\
\hline \multicolumn{2}{|l|}{ Atterrare - to land - it is landing } \\
\hline \multicolumn{2}{|l|}{ Scuotere/scrollare - to shake - he is shaking } \\
\hline \multicolumn{2}{|l|}{ Tagliare - to cut - she is cutting } \\
\hline \multicolumn{2}{|l|}{ Sparare - to shoot - he is shooting } \\
\hline \multicolumn{2}{|l|}{ Marciare - to murch - they are murching } \\
\hline \multicolumn{2}{|l|}{ Ridere - to laugh - he is laughing } \\
\hline \multicolumn{2}{|l|}{ Starnutire - to sneeze - he is sneezing } \\
\hline \multicolumn{2}{|l|}{ Fiorire - to blossom - it is blossoming } \\
\hline Scivolare - to slip - he is slipping & Sbocciare \\
\hline \multicolumn{2}{|l|}{ Fischiare - to whistle - he is whistleing } \\
\hline \multicolumn{2}{|l|}{ Scendere - to get off - he is getting off } \\
\hline \multicolumn{2}{|l|}{ Leccare - to lick - it is licking } \\
\hline \multicolumn{2}{|l|}{ Sollevare - to lift - he is lifting } \\
\hline Accarezzare - to caress - she is caressing & Alzare \\
\hline
\end{tabular}


Table 3 - Mean and median scores and cut-off value.

\begin{tabular}{|c|c|c|c|c|}
\hline & Mean (SD) & Median & Cut-off & $\begin{array}{l}\text { Equivalent } \\
\text { scores }\end{array}$ \\
\hline \multirow[t]{5}{*}{ Action naming test } & $44.87(3.77)$ & 45 & $\leq 36.86$ & 0 \\
\hline & & & From 36.87 to 40.98 & 1 \\
\hline & & & From 40.99 to 43.42 & 2 \\
\hline & & & From 43.43 to 45.75 & 3 \\
\hline & & & $\geq 45.76$ & 4 \\
\hline
\end{tabular}


Table 4 - Correction grid for Action naming test.

Age years

\begin{tabular}{|c|c|c|c|c|c|c|c|c|c|c|c|c|c|c|}
\hline Education, years & $\leq 25$ & $26-30$ & $31-35$ & $36-40$ & $41-45$ & $46-50$ & $51-55$ & $56-60$ & $61-65$ & $66-70$ & $71-75$ & $76-80$ & $81-85$ & $\geq 86$ \\
\hline$\leq 5$ & 0.1 & 0.4 & 0.7 & 1.1 & 1.5 & 1.8 & 2.1 & 2.5 & 2.8 & 3.2 & 3.5 & 3.9 & 4.1 & 4.4 \\
\hline $6-8$ & -1 & -0.5 & -0.1 & 0.2 & 0.5 & 0.8 & 1.1 & 1.6 & 2.4 & 2.2 & 2.6 & 2.9 & 3.3 & 3.5 \\
\hline $9-13$ & -2.4 & -2 & -1.6 & -1.3 & -1 & -0.7 & -0.4 & 0.1 & 0.4 & 0.7 & 1.1 & 1.5 & 1.7 & 2.1 \\
\hline $14-16$ & -3.3 & -3 & -2.5 & -2.2 & -2 & -1.5 & -1.2 & -0.9 & -0.6 & -0.1 & 0.1 & 0.6 & 0.9 & 1.3 \\
\hline$\geq 17$ & -3.4 & -3.3 & -2.9 & -2.6 & -2.2 & -1.9 & -1.5 & -1.2 & -0.8 & -0.5 & -0.1 & 0.2 & 0.5 & 1.5 \\
\hline
\end{tabular}


